\title{
A Vision for CBMS
}

\author{
David M. Bressoud
}

After almost a third of a century in which their names have become synonymous with the Conference Board of the Mathematical Sciences (CBMS), Ron Rosier and Lisa Kolbe retired from their respective positions as director and administrative coordinator on December 31, 2016. Our community owes them a tremendous debt of gratitude for their tireless work on behalf of the professional societies in the mathematical sciences, work that was always done with professionalism and style.

As the new director of CBMS, my first task is to maintain and continue to strengthen the projects that they have nurtured. The CBMS Executive Committee and I also see this as an opportune moment to build on the work begun in the Common Vision report ([1], [2]).

\section{What Is CBMS?}

Most mathematicians know CBMS either through the NSF-CBMS Regional Research Conferences, the Regional Conference Series monographs, or the Statistical Abstract of Undergraduate Programs in the Mathematical Sciences in the United States that CBMS publishes, jointly with the AMS, every five years. Less well known are its monograph series in Issues in Mathematics Education, the Mathematical Education of Teachers (MET II) report, the CBMS national forums on issues of mathematics education, or the statements issued jointly by the presidents of the member societies in support of the Common Core State Standards for Mathematics (2013), the Collective Effort to Improve the First Two Years of College Math (2015), or the Statement on Active Learning (2016). Information on all of these can be found on the CBMS website, cbmsweb.org.

CBMS grew out of informal meetings of the presidents of the societies in the mathematical sciences and was formally incorporated in 1960. Its core purpose is to provide a forum for these presidents to meet on a regular basis to share information about issues of common concern and to coordinate efforts. From its earliest days, it has taken

David Bressoud is director of CBMS and DeWitt Wallace Professor of Mathematics at Macalester College. His e-mail address is bressoud@macalester . edu.

For permission to reprint this article, please contact:

reprint-permission@ams.org.

DOI: http://dx.doi.org/10.1090/noti1535 on the role of providing a home for initiatives that are supported by multiple societies. The NSF-CBMS Regional Research Conferences was one of the first such efforts. Begun in 1969, the seven conferences being offered this summer will bring the 49-year total to 365 such five-day conferences and 221 monographs published by the AMS, SIAM, or IMS-ASA. Today, CBMS brings together 17 organizations. Among them are the major societies at the post-secondary and research level, those that operate primarily within $\mathrm{K}-12$, those that focus on issues of underrepresented groups, and those with less academically focused interests. A complete list of the member societies (with acronyms spelled out) is given at the end of this article.

CBMS is a skeletal organization, staffed by just two quarter-time employees, now Kelly Chapman and me. While it has long shared MAA's facilities in Washington, DC, the lean structure and the ability to draw on the resources of the member societies has enabled us to move its office to the campus of Macalester College in Saint Paul, MN, while continuing to hold the meetings of the society presidents in the Washington, DC area, currently at the American Statistical Association's headquarters in Alexandria, VA.

\section{The Opportunity}

CBMS is interested in all aspects of the profession. In education, the member societies span $\mathrm{K}-12$, undergraduate, graduate, and workplace concerns. As such, CBMS is uniquely positioned to address issues of transition: high school to college, two-year to four-year college, undergraduate to workplace, undergraduate to graduate, and graduate to both academic and non-academic employment. While these are all important, much of my own focus, as well as that of the member societies, has been on high school to college, grades 11 to 14 .

This is a uniquely opportune moment to work on these issues, following on the heels of several converging efforts: the Common Vision report, the Statement on Active 
Learning endorsed by the presidents of the CBMS member societies, the work by many of the member societies on the first two years of undergraduate instruction, and the involvement of the mathematics research community through TPSE Math (Transforming Post-Secondary Education in Mathematics), whose executive director, William (Brit) Kirwan, currently sits as chair of CBMS.

\section{An Agenda}

The immediate task before the societies is to transform their statements of support into concrete actions that will help bring about needed changes. I recognize two fronts along which this work must progress:

Research to help us understand our present situation and the true difficulties that must be tackled, especially with regard to encouraging and supporting women, students from underresourced schools, first-generation college students, and students from underrepresented minorities. We know much more about effective mathematics education and how to increase access than we did just ten years ago, but there are still huge gaps in our knowledge. As a first step, CBMS is now exploring the formation of a Research Advisory Group to catalog the broad spectrum of data and research that can inform mathematics education at all levels, identify the most important research questions that need to be answered, and look at how we can get relevant information into the hands of change leaders as we help them understand how to analyze and use this information.

Resources and Support for departments that recognize a need for change but require help understanding what they can and should do and how to accomplish these actions. The assistance that departmental leadership will need includes:

1. Information about what is happening at other institutions and within various networks across the country.

2. Guidance on how to evaluate the effectiveness of their own programs. This includes descriptions of the nature of data that should be collected and the various instruments that can be used to better understand what is happening within their own programs.

3. Networks of mutual support connecting comparable institutions that can share their experiences with obstacles and successes. This must include a structure that facilitates and maintains these networks. The experience of PULSE (Partnership for Undergraduate Life Science Education) provides one possible model.

4. Suggestions for and assistance in developing programs for graduate students heading into academia so that they are prepared to be effective teachers.

5. Regular national meetings of department chairs and departmental leaders to learn of recent developments, resources that have become available, and how other departments are facing issues of mutual concern.

Our agenda is ambitious but critically important. We live in a challenging time when major shifts in how we understand and conduct mathematics education are under way. Without active involvement by the professional societies, change will be shaped by those outside

our community. As an organization that fosters dialogue and cooperation among the societies, CBMS is uniquely positioned to help us take charge of our own future by identifying, promoting, and encouraging best practices across all of education in the mathematical sciences.

\section{References}

[1] T. HOLm and K. SAXE, A Common Vision for undergraduate mathematics, Notices Amer. Math. Soc., June/July 2016.

[2] K. SAXE and L. BRADDY, A Common Vision for Undergraduate Mathematical Sciences Programs in 2025, MAA, Washington, DC, 2015. Available at www.maa.org/programs/ faculty-and-departments/common-vision.

\section{The Societies of CBMS:}

AMATYC American Mathematical Association of TwoYear Colleges

AMS American Mathematical Society

AMTE Association of Mathematics Teacher Educators ASA American Statistical Association

ASL Association for Symbolic Logic

AWM Association for Women in Mathematics

ASSM Association of State Supervisors of Mathematics

BBA Benjamin Banneker Association

IMS Institute of Mathematical Statistics

INFORMS Institute for Operations Research and the Management Sciences

MAA Mathematical Association of America

NAM National Association of Mathematicians

NCSM National Council of Supervisors of Mathematics

NCTM National Council of Teachers of Mathematics

SIAM Society for Industrial and Applied Mathematics

SOA Society of Actuaries

TODOS TODOS: Mathematics for ALL

\section{Photo Credit}

Photo of David M. Bressoud is courtesy of Jan Bressoud.

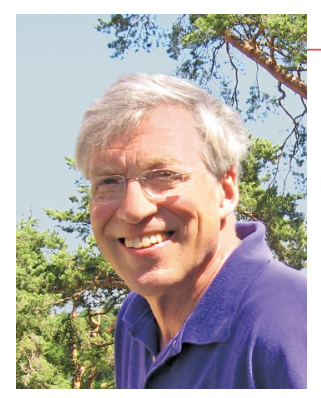

David M. Bressoud

\section{ABOUT THE AUTHOR}

David M. Bressoud is a Returned Peace Corps Volunteer (West Indies, 1971-73), who is most proud of his collaborations with George Andrews, his work with the AP Calculus program, and his successes at weaving the history of mathematics into his classes and textbooks. 